Original Article

\title{
Comparison of Maitland and Kaltenborn mobilization techniques for improving shoulder pain and range of motion in frozen shoulders
}

\author{
Gui Do Moon, MSc, $\mathrm{PT}^{1}$ ) , Jin Yong Lim, MSc, $\mathrm{PT}^{1)}$, DA Yeon Kim, PhD, $\mathrm{PT}^{1)}$, \\ TAE Ho Kim, PhD, $\mathrm{PT}^{1)^{*}}$ \\ 1) Department of Physical Therapy, College of Rehabilitation Science, Daegu University: 15 Jilyang, \\ Gyeongsan-si, Gyeongsangbuk-do 712-714, Republic of Korea
}

\begin{abstract}
Purpose] This study compared the use of the Maitland mobilization and Kaltenborn mobilization techniques for improving pain and range of motion in patients with frozen shoulders. [Subjects and Methods] The subjects were 20 patients with frozen shoulder who visited Hospital H, Ulsan, Korea. The subjects were divided randomly into two groups to receive Maitland or Kaltenborn mobilization to the affected shoulder. Grade III anteroposterior oscillation and posterior translation were used for the Maitland and Kaltenborn mobilization groups, respectively. Pain and range of motion of external and internal rotation were evaluated pre- and post-intervention in both groups. Paired t-tests were used to compare the pre- and post-intervention results in both groups, and independent t-tests were used to compare groups. [Results] Both groups exhibited significant decreases in pain post-intervention. Moreover, the range of motion of internal and external rotation increased significantly post-intervention in both groups. However, there was no significant difference between groups with respect to pain improvement or range of motion. [Conclusion] The posterior Maitland and Kaltenborn mobilization techniques are effective for improving pain and range of motion in frozen shoulder patients. Therefore, we recommend both techniques for such patients. Key words: Maitland mobilization, Kaltenborn mobilization, Frozen shoulder
\end{abstract}

(This article was submitted Dec. 5, 2014, and was accepted Jan. 11, 2015)

\section{INTRODUCTION}

Frozen shoulder (FS), more formally termed adhesive capsulitis, is a disease that causes tissue degeneration, joint capsule thickening, and diminished glenoid cavity volume $^{1)}$. It is one of the most frequently observed shoulder diseases in clinical settings. FS has various etiologies such as periarticular tissue degenerative changes, synovial joint thickening, articular surface adhesion, etc ${ }^{2}$. FS is usually divided into the following three stages: (1) severe pain, (2) gradual restrictions in range of motion (ROM) accompanied by pain, and (3) pain resolution and ROM recovery ${ }^{3}$. The disease causes slowly increasing pain and gradually decreasing ROM, creating difficulty performing daily activities. Its incidence is higher among office workers than laborers and higher among females than males; the non-dominant shoulder is more likely to develop $\mathrm{FS}^{4)}$. FS was previously thought to heal naturally one to two years after occurrence. However, as it became obvious that the disability persists without adequate treatment, various treatment methods have

*Corresponding author. Tae Ho Kim (E-mail: ptkimth@ daegu.ac.kr)

(C2015 The Society of Physical Therapy Science. Published by IPEC Inc. This is an open-access article distributed under the terms of the Creative Commons Attribution Non-Commercial No Derivatives (by-ncnd) License $<$ http://creativecommons.org/licenses/by-nc-nd/3.0/> . been proposed ${ }^{5,6)}$

The most effective surgical or medical treatment strategy for ROM recovery in FS patients remains controversial ${ }^{7}$. However, physiotherapy is frequently performed for FS treatment; treatment programs comprising exercise, massage, and modality are reported to improve all aspects of shoulder ROM with the exception of external and internal rotation $^{8)}$.

Clinically, FS causes losses of passive and active ROM of the shoulder; external rotation usually shows the most severe loss. There are the previous studies for the application of joint mobilization related to the rotation defect of shoulder joint among FS patients. Joint mobilization, which is often used to treat FS patients, can be divided into the oscillatory technique suggested by Maitland ${ }^{9}$ and the sustained stretch technique suggested by Kaltenborn ${ }^{3}$. The Maitland mobilization (MM) and Kaltenborn mobilization (KM) techniques are both passive treatments, but they differ in that MM uses oscillation while KM uses sustained stretching.

MM applies a passive oscillatory technique, classified from Grade I-IV with respect to intensity, to the shoulder in order to treat pain and stiffness. Grade I refers to an intensity of small amplitude that is applied at the beginning of the joint ROM, where there is no loading on connective tissue; it is often used in cases of severe pain. Meanwhile, Grade II refers to an intensity of slightly larger amplitude applied from the beginning of the joint ROM to the middle. Grade I and II oscillation stimuli provoke the mechanical receptor 
of the joint, restricting the nocuous stimulus that generates the pain stimulus, which is transmitted to the central nervous system; therefore, it is appropriate for relieving pain. Grade III is applied at a large amplitude from the middle of the joint ROM to the beginning of the restriction. Finally, Grade IV is applied against the tissue resistance at a small amplitude to the restricted part of the joint. Grade III and IV oscillation stimuli are used for provoking a stretching to relieve joint stiffness by applying in a shorter tissue.

On the other hand, KM evaluates the motions on the articular surface and applies them to treatment according to MacConaill's classification, which posits most articular surfaces have convex interiors and concave exteriors ${ }^{10)}$. $\mathrm{KM}$ involves the application of a passive sustained stretch technique to enhance joint mobility without articular surface suppression. The forces applied to increase joint mobility are graded from I-III. Grade I applies a distraction of minor intensity that hardly causes stress within the joint capsule; it is often used to decrease pain. Grade II refers to a force that stretches the periarticular tissue; such stimulus is colloquially referred to as "taking up the slack." Finally, Grade III force causes enough distraction or gliding so that joint capsule can sufficiently stretch; it is often used for enhancing $\mathrm{ROM}^{11,12)}$.

Several studies have investigated the treatment effects of joint mobilization to the shoulders of FS patients. Maricar and $\mathrm{Chok}^{13)}$ report no significant difference in the treatment effects between MM and another exercise program in a study of FS patients. Vermeulen et al. ${ }^{14)}$ argue that the application of MM from diverse directions rather than a single direction to FS patients' shoulders improves abduction, flexion, and external rotation ROM. Moreover, the application of KM to FS patients usually improves shoulder $\mathrm{ROM}^{15)}$. Despite the several studies on passive joint mobilization in FS patients, few studies have compared MM using oscillation and KM using sustained stretching.

Therefore, this study compared the effects of MM and $\mathrm{KM}$ for improving the pain and ROM of FS patients.

\section{SUBJECTS AND METHODS}

The study subjects were 20 FS patients who visited Hospital H located in Ulsan, Korea. Patients' diagnosis, age, gender, affected area, duration, etc. were collected from medical records and by interviews. The inclusion criteria were a diagnosis of FS or adhesive capsulitis, more than two passive ROMs (i.e., anterior flexion, frontal abduction, and external rotation at $0^{\circ}$ abduction) of a damaged shoulder showing a loss of over $50 \%$ compared to the non-damaged side $^{16)}$, increasing restriction of the shoulder's external rotation ROM following an increase in shoulder abduction, no history of surgery to the damaged shoulder, no manipulation of the damaged shoulder under anesthesia, and pain lasting at three months. Patients with shoulder mobility defects accompanying neurological damage, such as in stroke or Parkinson's disease, as well as those with diabetes, rheumatism, osteoporosis, surgical fixation, malignant tumors, or radiating pain from a cervical lesion were excluded.

We clarified whether the patients' shoulder ROM restrictions were due to muscle contraction or the joint capsule.
Table 1. General characteristics of the patients $(N=20)$

\begin{tabular}{lcr}
\hline & Kaltenborn & \multicolumn{1}{c}{ Maitland } \\
\hline Age $($ years $)$ & $48.3 \pm 2.98$ & $49.1 \pm 3.07$ \\
Height $(\mathrm{cm})$ & $169.8 \pm 4.1$ & $170.9 \pm 2.23$ \\
Weight $(\mathrm{kg})$ & $67.9 \pm 7.37$ & $69.6 \pm 4.58$ \\
BMI $(\mathrm{cm} / \mathrm{kg})$ & $23.58 \pm 2.66$ & $23.86 \pm 1.92$ \\
Pain $(\mathrm{VAS}, 0-10)$ & $5.58 \pm 0.80$ & $6.05 \pm 1.12$ \\
Symptom duration (months) & $7.85 \pm 1.27$ & $8.15 \pm 1.25$ \\
Internal rotation $\left(^{\circ}\right)$ & $31.98 \pm 6.17$ & $31.74 \pm 6.77$ \\
External rotation $\left(^{\circ}\right)$ & $38.8 \pm 5.75$ & $40.85 \pm 7.51$ \\
\hline
\end{tabular}

Mean \pm SD. BMI: body mass index, VAS: visual analog scale

According to clinical experience and cadaveric experiments ${ }^{17)}$, we defined joint capsule tightness as a shoulder external rotation defect that becomes more severe following shoulder abduction. If the shoulder external rotation ROM defect is unaffected by the shoulder's abduction, it might be due to muscle flexibility. Therefore, patients showing no change in external rotation ROM following abduction were excluded from the study.

After providing a sufficient explanation of the experimental process, patients who volunteered to participate in the study provided written informed consent. In accordance with the Declaration of Helsinki, this study was approved by the Ethics Committee of Daegu University. The general characteristics of the subjects are summarized in Table 1.

A visual analogue scale (VAS) was used to measure pain intensity pre- and post-intervention. Bulgen et al. ${ }^{18)}$ report that it is difficult to recognize patient pain, because FS patients tend to complain about pain during motion, even though they possess chronic pain. Therefore, to measure pain intensity, each patient was instructed to execute shoulder flexion, internal rotation, and external rotation three times and then directly note the pain intensity. Regarding quantification, the patient marked the pain intensity he/she felt on a $10-\mathrm{cm}$ line; the left end indicated no pain ( 0 points $)$, and the right end indicated the maximum pain intensity (10 points). The VAS is a reliable (intraclass correlation coefficient $=0.99$ ) and valid pain evaluation tool ${ }^{19)}$ that is widely used in clinical practice.

A digital goniometer was used to measure the passive ROM of the shoulder's internal and external rotation preand post-intervention. With the patient in the supine position, passive joint ROM was measured with the elbow joint at $90^{\circ}$ flexion, external rotation at $90^{\circ}$ abduction, and internal rotation at $90^{\circ}$ abduction. The angle between the forearm and a line vertical to the therapeutic table was measured. However, as the majority of FS patients presented with broad shoulder ROM defects with shoulder abduction limited to less than $90^{\circ}$, the rotation was performed at the maximum degree possible when $90^{\circ}$ was not possible. The tester recorded the baseline abduction degree of the shoulder of each subject, which was always passively located at the baseline abduction degree before measurement. This method was chosen because of the variability in the ROM defect in FS patients. Any abnormal movement in the scapula was prevented in order to maintain a stable shoulder abduction degree. The 
Table 2. Changes in pain and rotation ROM pre- and post-intervention

\begin{tabular}{lcrrr}
\hline & \multicolumn{2}{c}{ Kaltenborn $(\mathrm{n}=10)$} & \multicolumn{2}{c}{ Maitland $(\mathrm{n}=10)$} \\
\hline & Pre & Post & Pre & Post \\
\hline Pain (VAS) & $5.58 \pm 0.8$ & $2.65 \pm 0.67^{*}$ & $6.05 \pm 1.12$ & $3.12 \pm 0.98^{*}$ \\
Internal rotation $\left(^{\circ}\right)$ & $31.98 \pm 6.17$ & $37.32 \pm 7.76^{*}$ & $31.74 \pm 6.77$ & $36.84 \pm 6.90^{*}$ \\
External rotation $\left(^{\circ}\right)$ & $38.8 \pm 5.75$ & $49.64 \pm 5.17^{*}$ & $40.85 \pm 7.51$ & $49.76 \pm 8.64^{*}$ \\
\hline Mean \pm SD. VAS: visual analog scale. & & &
\end{tabular}

$* p<0.05$, pre- vs. post-intervention.

humerus moved passively while maintaining a neutral position. Next, in order to measure the external and internal rotations, the coracoid and clavicle were pressed by one hand to stabilize the scapula, while the forearm was rotated toward the foot and head in cases of internal and external rotation, respectively, by the other hand to measure the passive joint ROM. The point where forearm rotation stopped differed in each patient according to the point where the tester detected an end feel or the patient felt too much pain to move further $^{20)}$. An assistant tester placed the digital inclinometer on the dorsal side of the forearm such that it was parallel to the major axis of the backbone. In order to exclude the effects of joint mobilization during measurement, a one-minute rest period was allowed after each measurement. The average value of three measurements was used for the analysis.

The patients were randomly assigned to one of two therapists. A sealed box containing cards with numbered 1 or 2 was prepared, and the patients chose one card; patients with cards numbered 1 and 2 were allocated to the Kaltenborn group $(n=10)$ and Maitland group $(n=10)$, respectively. Each patient underwent testing before the experiment in order to evaluate pain intensity and shoulder joint ROM. When the treatment began, a hot pack was applied to the affected shoulder for 20 minutes, followed by interferential current treatment for 15 minutes $^{21)}$. Each joint mobilization exercise was subsequently performed. The treatment was performed by a clinical physiotherapist with more than 10 years' experience with joint mobilization therapy. Patients received a total of 12 therapy sessions three times per week for four weeks.

Each patient's pain and ROM were evaluated four weeks after therapy. The patients were recommended to use their arms and shoulders within the possible ROM in daily activities, although they did not receive a home-based exercise program.

For joint mobilization, one of the manual therapies of KM Grade III posterior translation was used. As mentioned above, KM Grade III refers to sustained stretching at an intensity at which the joint capsule is stretched. With the patient in the supine position, the damaged scapula was fixated by placing a wedge underneath. The therapist executed maximum abduction of the humerus using one hand while standing beside the patient. After executing $90^{\circ}$ flexion of the elbow joint, the forearm was rotated toward the head so that it was located at the end range of the glenohumeral joint. Next, posterior translation was applied to the humeral head using the other hand. The translation was applied a set for 30 seconds for 15 sets over 10 minutes; after each set, the patient rested in a neutral position for approximately 10 seconds.

For additional joint mobilization, one of the manual therapies of MM Grade III anteroposterior oscillation was used $^{9)}$. MM Grade III is applied at an intensity that slightly exceeds the restriction point of the ROM to provoke tissue resistance, involving an oscillation movement with slow and large amplitude; it improves joint mobilization by inducing joint capsule and connective tissue stretching ${ }^{22)}$. With the patient in the supine position, the damaged scapula was fixated by placing a wedge underneath. The therapist executed maximum abduction of the humerus using one hand while standing beside the patient. After executing $90^{\circ}$ flexion of the elbow joint, the forearm was rotated toward the head so that it was located at the end range of the shoulder joint. Afterwards, anteroposterior oscillation was applied to the humeral head using the other hand. The oscillation was one per second applied for a total of fifteen 30 -second sets for 10 minutes $^{23)}$; after each set, the patient was allowed to rest in the neutral position for approximately 10 seconds.

SPSS version 18.0 was used for all statistical analyses. Prior to analysis, data normality was tested by the ShapiroWilk test. A paired t-test was used to compare pre- and postintervention data in each group, and an independent t-test was used to compare the MM and KM groups. The level of significance in all analyses was set at $\alpha<0.05$.

\section{RESULTS}

There were significant differences in pain and the ROM of both internal and external shoulder rotation pre- and postintervention in the MM and KM groups $(\mathrm{p}<0.05)$ (Table 2). However, there were no significant differences between the $\mathrm{MM}$ and $\mathrm{KM}$ groups with respect to pain or ROM improvement in FS patients $(\mathrm{p}>0.05)$ (Table 2$)$.

\section{DISCUSSION}

The results indicate the oscillatory technique in MM and sustained stretch technique in KM combined with therapeutic modalities were both effective for treating external and internal rotation ROM deficits frequently observed among FS patients as well as reducing pain.

In clinical practice, physical therapists have traditionally used anterior translation of the humeral head following the convex-concave rule in order to recover the shoulder's external rotation ROM. However, several studies demonstrate posterior translation is more effective than anterior translation for external rotation ROM recovery ${ }^{15,24)}$. Roubal et al. ${ }^{24)}$ applied posterior translation to improve shoulder rota- 
tion based on the "capsular constraint mechanism," while Johnson et al. ${ }^{15)}$ argue that posterior gliding is more efficient than anterior gliding for improving external rotation ROM among FS patients. However, Vermeulen et al. ${ }^{15)}$ compared the effects of high- and low-grade mobilization techniques on FS patients and report that the former are more effective for shoulder ROM improvement and malfunction reduction. Therefore, posterior joint mobilization was selected for the present study with an intensity of Grade III.

Both the MM and KM groups showed decreases in pain post-intervention, and joint mobilization exhibited a hypoalgesic effect ${ }^{25}$ ). Various mechanisms explaining the pain reduction after joint mobilization have been proposed. Mangus et al. ${ }^{26)}$ argue that joint mobilization controls pain through neurophysiological effects by stimulating type II mechanoreceptors while inhibiting type IV nociceptors. Passive joint mobilization provokes Golgi tendon organ activity at the end of the joint mobilization and causes reflex inhibition of the muscle ${ }^{27}$. Decreased muscle activity after joint mobilization decreases joint concentric activation, alleviating pain and muscle tension in periarticular tissue ${ }^{28)}$. However, the mechanisms underlying the reduction in pain observed in the present study remain unclear.

In the case of KM Grade III posterior translation, both the external and internal rotation ROMs increased after the intervention. Harryman et al. ${ }^{29)}$ conducted a cadaveric experiment to determine if a tightened rotator cuff interval affected the translation of the humeral head during the movement of the humerus. Joint capsule contracture is frequently observed in rotator cuff intervals among FS patients ${ }^{30)}$. Their results indicate that a tight rotator cuff interval causes undesirable anterosuperior translation and eventually limits the ROM by restricting the posterior translation during external rotation. Hence, the result of the present study are consistent with those of Roubal et al. ${ }^{24)}$ and Johnson et al. ${ }^{15)}$ in that external rotation was enhanced by increasing posterior translation through rotator cuff interval stretching. Moreover, contracture of the shoulder posterior capsule is known to cause internal rotation reduction in abduction at $90^{\circ 31)}$. Gong et al. ${ }^{32)}$ observed that posterior translation is effective for increasing shoulder internal rotation in normal individuals. Thus, the posterior translation applied in the present study likely contributed to the increased internal rotation by stretching the posterior capsule.

In the case of the Grade III anteroposterior oscillation in $\mathrm{MM}$, both the external and internal rotation ROMs increased significantly post-intervention, similar to that after KM. This can be interpreted to mean that MM provokes tissue stretching even though it uses oscillation and produces results similar to those of KM.

The limitations of this study are as follows. First, the sample size was not large enough to generalize the study results to other populations. Second, even though patients were selected according to strict inclusion criteria, the strength of the third stage of mobilization differed according to each patient's recovery. Third, the study allowed all movements during daily activities and was therefore unable to control for the diverse motions of each patient. Finally, the direction of mobilization applied for treatment was not diverse enough. Future studies involving FS patients should investigate mobilization in various directions in addition to posterior mobilization.

In summary, anteroposterior $\mathrm{MM}$ and $\mathrm{KM}$ reduced pain and improved ROM in FS patients. Therefore, these techniques are effective for improving FS-associated joint contracture and pain. However, there was no significant difference between the MM and KM techniques with respect to pain reduction or ROM improvement. Therefore, we recommend both anteroposterior MM and KM be considered for ROM improvement and pain reduction among FS patients.

\section{ACKNOWLEDGEMENT}

This research was supported by the Daegu University Research Grant, 2012.

\section{REFERENCES}

1) Wadsworth CT: Frozen shoulder. Phys Ther, 1986, 66: 1878-1883. [Medline]

2) Akpinar S, Ozalay M, Hersekli MA, et al.: [Arthroscopic capsular release for frozen shoulder]. Acta Orthop Traumatol Turc, 2003, 37: 213-218. [Medline]

3) Kisner C, Colby LA: Therapeutic exercise: foundations and techniques, 5th ed. Philadelphia: FA Davis, 2012, pp 324-329.

4) Shaffer B, Tibone JE, Kerlan RK: Frozen shoulder. A long-term follow-up. J Bone Joint Surg Am, 1992, 74: 738-746. [Medline]

5) Levy O, Rath E, Atar D: [Combined treatment for adhesive capsulitis of the shoulder]. Harefuah, 1997, 133: 357-359, 415. [Medline]

6) Yang JL, Chang CW, Chen SY, et al.: Mobilization techniques in subjects with frozen shoulder syndrome: randomized multiple-treatment trial. Phys Ther, 2007, 87: 1307-1315. [Medline] [CrossRef]

7) Loew M, Heichel TO, Lehner B: Intraarticular lesions in primary frozen shoulder after manipulation under general anesthesia. J Shoulder Elbow Surg, 2005, 14: 16-21. [Medline] [CrossRef]

8) Jürgel J, Rannama L, Gapeyeva H, et al.: Shoulder function in patients with frozen shoulder before and after 4-week rehabilitation. Medicina (Kaunas), 2005, 41: 30-38. [Medline]

9) Maitland GD: Treatment of the glenohumeral joint by passive movement. Physiotherapy, 1983, 69: 3-7. [Medline]

10) MacConaill MA: The movements of bones and joints. V. The significance of shape. J Bone Joint Surg Br, 1953, 35-B: 290-297. [Medline]

11) Kaltenborn F: Fisioterapia Manual, Columna, 2nd ed. Madrid-España: McGraw-Hill. Interamericana, 2004, pp 27-28.

12) Villafañe JH, Fernandez de-Las-Peñas C, Silva GB, et al.: Contralateral sensory and motor effects of unilateral kaltenborn mobilization in patients with thumb carpometacarpal osteoarthritis: a secondary analysis. J Phys Ther Sci, 2014, 26: 807-812. [Medline] [CrossRef]

13) Maricar N, Chok B: A comparison of the effect of manual therapy with exercise therapy and exercise therapy alone for stiff shoulders. Physiother Singap, 1999, 2: 99-104

14) Vermeulen HM, Obermann WR, Burger BJ, et al.: End-range mobilization techniques in adhesive capsulitis of the shoulder joint: A multiple-subject case report. Phys Ther, 2000, 80: 1204-1213. [Medline]

15) Johnson AJ, Godges JJ, Zimmerman GJ, et al.: The effect of anterior versus posterior glide joint mobilization on external rotation range of motion in patients with shoulder adhesive capsulitis. J Orthop Sports Phys Ther, 2007, 37: 88-99. [Medline] [CrossRef]

16) Vermeulen HM, Rozing PM, Obermann WR, et al.: Comparison of highgrade and low-grade mobilization techniques in the management of adhesive capsulitis of the shoulder: randomized controlled trial. Phys Ther, 2006, 86: 355-368. [Medline]

17) Ovesen J, Nielsen S: Stability of the shoulder joint. Cadaver study of stabilizing structures. Acta Orthop Scand, 1985, 56: 149-151. [Medline] [CrossRef]

18) Bulgen DY, Binder AI, Hazleman BL, et al.: Frozen shoulder: prospective clinical study with an evaluation of three treatment regimens. Ann Rheum Dis, 1984, 43: 353-360. [Medline] [CrossRef]

19) Gallagher EJ, Bijur PE, Latimer C, et al.: Reliability and validity of a visual analog scale for acute abdominal pain in the ED. Am J Emerg Med, 2002, 20: 287-290. [Medline] [CrossRef] 
20) Andrews AW, Bohannon RW: Decreased shoulder range of motion on paretic side after stroke. Phys Ther, 1989, 69: 768-772. [Medline]

21) Kurtaiş Gürsel Y, Ulus Y, Bilgiç A, et al.: Adding ultrasound in the management of soft tissue disorders of the shoulder: a randomized placebocontrolled trial. Phys Ther, 2004, 84: 336-343. [Medline]

22) Cleland JA, Childs JD, McRae M, et al.: Immediate effects of thoracic manipulation in patients with neck pain: a randomized clinical trial. Man Ther, 2005, 10: 127-135. [Medline] [CrossRef]

23) Teixeira LM, Pires T, Silva RD, et al.: Immediate effect of a single anteroposterior talus mobilization on dorsiflexion range of motion in participants with orthopedic dysfunction of the ankle and foot. J Manipulative Physiol Ther, 2013, 36: 369-375. [Medline] [CrossRef]

24) Roubal PJ, Dobritt D, Placzek JD: Glenohumeral gliding manipulation following interscalene brachial plexus block in patients with adhesive capsulitis. J Orthop Sports Phys Ther, 1996, 24: 66-77. [Medline] [CrossRef]

25) Sluka KA, Skyba DA, Radhakrishnan R, et al.: Joint mobilization reduces hyperalgesia associated with chronic muscle and joint inflammation in rats. J Pain, 2006, 7: 602-607. [Medline] [CrossRef]

26) Mangus B, Hoffman L, Hoffman M, et al.: Basic principles of extremity joint mobilization using a Kaltenborn approach. J Sport Rehabil, 2002, 11: 235-250.

27) Lundberg A, Malmgren K, Schomburg ED: Role of joint afferents in motor control exemplified by effects on reflex pathways from Ib afferents. J Physiol, 1978, 284: 327-343. [Medline] [CrossRef]

28) Zusman M: Spinal manipulative therapy: review of some proposed mechanisms, and a new hypothesis. Aust J Physiother, 1986, 32: 89-99. [Medline] [CrossRef]

29) Harryman DT 2nd, Sidles JA, Harris SL, et al.: The role of the rotator interval capsule in passive motion and stability of the shoulder. J Bone Joint Surg Am, 1992, 74: 53-66. [Medline]

30) Zhao W, Zheng X, Liu Y, et al.: An MRI study of symptomatic adhesive capsulitis. PLoS ONE, 2012, 7: e47277. [Medline] [CrossRef]

31) Burkhart SS, Morgan CD, Kibler WB: The disabled throwing shoulder: spectrum of pathology Part I: pathoanatomy and biomechanics. Arthroscopy, 2003, 19: 404-420. [Medline] [CrossRef]

32) Gong $W$, Lee H, Lee Y: Effects of Gong's mobilization applied to shoulder joint on shoulder abduction. J Phys Ther Sci, 2011, 23: 391-393. [CrossRef] 